\title{
Aquatic physiotherapy in the functional capacity of elderly with knee osteoarthritis
}

\author{
Fisioterapia aquática na \\ capacidade funcional de idosos \\ com osteoartrite de joelho
}

\begin{abstract}
Fernando Pereira Garbi (1) ${ }^{1}$
Paulo Roberto Rocha Júnior (1D ${ }^{1 *}$

Natália de Souza Pontes (D) ${ }^{1}$

Andressa de Oliveira (1D ${ }^{1}$

Glauber de Oliveira Barduzzi (D) ${ }^{2}$

Paulo José Fortes Villas Boas (10 ${ }^{3}$
\end{abstract}

${ }^{1}$ Centro Universitário de Adamantina (UniFAl), Department of Physiotherapy, Adamantina, SP, Brazil

2 University College Dublin, School of Public Health, Physiotherapy and Population Science, Dublin, Ireland

${ }^{3}$ Universidade Estadual Paulista (UNESP), Botucatu School of Medicine,

Department of Public Heatlh, Botucatu, SP, Brazil

Date of first submission: March 16, 2021

Last received: July 28, 2021

Accepted: August 11, 2021

Associate editor: Mariana Asmar Alencar Collares

*Correspondence: paulorochajr@fai.com.br

\begin{abstract}
Introduction: Physicaltherapy in patients with osteoarthritis (OA) acts to decrease pain, increase joint functionality and to promote improvement in quality of life. Objective: To analyze the effect of a structured program of aquatic physiotherapy (AP) on functional capacity (FC) and mobility of elderly people with OA. Methods: Prospective, quantitative and analytical, randomized control study. The sample consisted of 29 patients, aged 60 years or over, diagnosed with OA, randomly allocated to the intervention group (IG), composed of 17 participants who underwent BP for two months, and to the control group (CG) of 12 participants. The primary outcome was measured by the WOMAC instruments and six-minute walk test. As a secondary endpoint, the Timed Up and Go Test measured mobility. Descriptive statistical analysis was used to present the data, with mean and standard deviation values. The comparison between groups for potential confounding factors and in relation to evolution was performed using the non-parametric chisquare test, Fisher's exact test and the Kruskal-Wallis test, and Dunn's test for multiple comparisons. The differences were considered statistically significant when $p<0.05$. Results: There was a significant difference in physical and functional parameters related to pain $(p<0.001)$, stiffness ( $p<0.001)$ physical activity $(p<0.001)$, distance covered in six minutes $(p=0.001)$, and mobility $(p<0.001)$ when comparing IG to CG. Conclusion: The structured AP program effectively contributed to the improvement of FC and mobility of elderly people with knee OA.
\end{abstract}

Keywords: Osteoarthritis. Physical Therapy modalities. Aged. 


\section{Resumo}

Introdução: A fisioterapia em pacientes com osteoartrite (OA) atua na diminuição da dor, aumento da funcionalidade articular e promove melhora na qualidade de vida. Objetivo: Analisar o efeito de um programa estruturado de fisioterapia aquática (FA) na capacidade funcional (CF) e mobilidade de idosos com OA. Métodos: Estudo de controle prospectivo, quantitativo e analítico, randomizado. A amostra foi composta por 29 pacientes com idade igual ou superior a 60 anos e com diagnóstico de OA alocados aleatoriamente no grupo intervenção, composto por 17 participantes submetidos à PA por dois meses, e no grupo controle de 12 participantes. O desfecho primário foi medido pelos instrumentos WOMAC e teste de caminhada de seis minutos. Como desfecho secundário, o Timed Up and Go Test mediu a mobilidade. Análise estatística descritiva foi utilizada para apresentar os dados, com valores de média e desvio padrão. A comparação entre os grupos para potenciais fatores de confusão e em relação à evolução foi realizada com o teste qui-quadrado não paramétrico, o teste exato de Fisher e o teste de Kruskal-Wallis, e o teste de Dunn para comparações múltiplas. As diferenças foram consideradas estatisticamente significantes quando $p<0,05$. Resultados: Observou-se diferença significativa nos parâmetros físicos e funcionais relacionados à dor $(p<0,001)$, rigidez ( $p<0,001)$ atividade física ( $p<0,001)$, distância percorrida em seis minutos $(p=0,001)$ e mobilidade $(p<0,001)$ quando comparado o IG ao GC. Conclusão: O programa estruturado de FA contribuiu efetivamente para a melhoria da CF e mobilidade de idosos com OA de joelho.

Palavras-chave: Osteoartrite. Modalidades de fisioterapia. Idoso.

\section{Introduction}

The aging of the population occurs on a global scale. In Brazil, the number of elderly people was $16 \%$, surpassing the mark of 34 million in $2019 .{ }^{1}$

Longevity brings within chronic degenerative diseases that limits the functional capacity (FC) of affected population. Osteoarthritis (OA), a chronic degenerative disease of high prevalence, is a musculoskeletal disorder usually with insidious, progressive and slow pattern, which typically affects the joints such as hands, spine, hip and knees. ${ }^{2}$ It is the most common joint disorder, affecting between $6 \%$ and $12 \%$ of adult population and more than a third of those who are aged 65 years or more. ${ }^{3}$ In addition to aging, obesity, trauma, joint surgery, hormonal imbalance, heredity, nutrition and bone density are some of the factors that predispose to OA. ${ }^{2}$

Signs and symptoms related to $O A$ in the population are related to: pain during the day, with relief when the individual is at rest; swelling and tenderness in the joints with or without the presence of crackles; morning stiffness and decreased range of motion, with decreased aerobic work capacity; and muscle weakness in the lower limbs. ${ }^{4}$ In addition to pain and stiffness, knee OA can impact mobility in the elderly, resulting in significant impairment of functional capacity. ${ }^{5}$

Physiotherapy's main objectives in patients with OA are to decrease pain, increase joint functionality and consequently promote improvement on the patient quality of life. The physiotherapist has several nonpharmacological resources to achieve those goals, such as the use of kinesiotherapy, manual therapy and electro thermal therapy. ${ }^{6}$ In this perspective, aquatic physiotherapy (AP) appears as a therapeutic resource widely used for the treatment of rheumatic diseases, as it facilitates the movements and reduces joint overload. ${ }^{7,8}$ Various therapeutic effects are achieved with immersion in warm water, such as muscle relaxation, analgesia and reduction of joint impact. ${ }^{9}$ Therefore, based on clinic and scientific evidence, the study was developed in order to verify the effects of a structured protocol of AP in the FC and mobility of elderly participants with knee OA.

\section{Methods}

\section{Design overview}

This study was a prospective, quantitative and analytical clinical trial of randomized control, which is interested in the prognostic factor of a therapeutic intervention. It was approved by the Ethics Committee of the Faculty of Medicine of Botucatu (UNESP), protocol 4269/2012, and registered by the Clinical Trials Registration Number: UTN Number - U1111-1157-9025.

\section{Population of the study}

Voluntary participants of both genders, with clinic and radiologic diagnosis of knee $\mathrm{OA}$, were referred to the physiotherapy department at Centro Universitário de Adamantina (UniFAl), São Paulo, Brazil. To be included, 
they were required to have age equal or above 60 years, and diagnosis of knee OA according to the American College of Rheumatology criteria (ACR). ${ }^{10}$ They were excluded if they had other kind of associated disease that primarily affected the lower limbs (ankylosing spondylitis, rheumatoid arthritis, neurodegenerative or neurological diseases), surgical knee history in the previous year, physiotherapy treatment in the last six weeks, contraindications to the $A P, O A$ functional class IV or who did not accept the terms and conditions of the research.

The required number of participants was performed by statistical calculation based on the prevalence of knee arthrosis in the population over 55 years old, ${ }^{11}$ and epidemiological data obtained by the IBGE during the 2010 census in the municipality of Adamantina, SP. ${ }^{12} \mathrm{~A}$ margin of error of $7 \%(a=0.07)$ and a reliability of $90 \%$ $(\beta=0.10)$ were considered. Twenty-nine elderly people $(n=29)$ with knee OA participated in the study.

\section{Randomization}

Randomization was performed with SAS for Windows, v.9.1.8, and distributed between the IG, where participants underwent AP and stretching, and CG, where participants did not receive any physiotherapy.

The draw was carried out by a physiotherapist who did not participate in the execution of the research, the allocation being informed to the volunteer through telephone contact on the same day as the draw. The intervention group (IG) was composed of fifteen women and two men ( $n=17$ ), and the control group ( $C G$ ) was composed of ten women and two men $(n=12)$. The CG group had 16 participants at the beginning, but four of them dropped out of the research; three for giving up and one for having undergone knee infiltration.

\section{Outcome measures}

The instrument Western Ontario and Macmaster Universities Osteoarthritis Index (WOMAC) $)^{13-15}$ evaluated the FC and six-minute walk test $(6 \mathrm{MWT})^{16}$ and the Timed Up and Go Test (TUG) measured the mobility. ${ }^{17,18}$ The collection took place in two stages (initial evaluation and after two months). Each of the steps was performed by the same evaluator. Initial evaluation: on the first day, sociodemographic data and the 6MWT were obtained. On the second day, the WOMAC questionnaire, the TUG and the functional classification based on the ACR criteria were applied. Evaluation after two months: the same procedures were repeated after the end of the treatment protocols in a maximum of seven days.

\section{Interventions}

The activities of the IG program (Table 1) were performed in the hydrotherapy sector of UniFAl, São Paulo, Brazil, that is equipped with cloakroom, lighting, and water equipment such as spaghetti, steps, ankle weights, triangular dumbbells, cervical and pelvic vests.

Table 1 - Description of the exercises in the aquatic physiotherapy program and stretching

\begin{tabular}{ll}
\hline Exercise & Description \\
\hline Heating & Free walk to adapt to the environment and bicycle with the aid of spaghetti. \\
Muscle strengthening & Quadriceps and hamstrings with the aid of flotation anklets. \\
\hline Stretching & $\begin{array}{l}\text { Patients were instructed to maintain a slow respiratory rhythm and to avoid } \\
\text { compensations, respecting each one's limit and possibility. }\end{array}$ \\
Buttocks & $\begin{array}{l}\text { Patients with their back to the bar and hands resting on the anterior region of the knee } \\
\text { perform maximum hip flexion. } \\
\text { Suadriceps }\end{array}$ \\
Supported patients perform knee flexion with the hand on the back of the foot, \\
preferably contralateral, bringing the heel towards the gluteus. \\
Patients at the bar raises one leg with the knee in extension supporting the foot against \\
the wall of the pool. Lean the torso forward and flex the hips until feeling a slight stretch \\
in the back of the thigh. Keep the spine and shoulders aligned. \\
Patients supported on the bar leans forward with one knee flexed and the other in \\
extension. The feet must be in contact with the ground and facing forward.
\end{tabular}


The AP program was conducted over a period of two months, totaling sixteen sessions with approximately 60 minutes each. The activities were carried out by two examiners, one responsible for collecting the initial data and supporting the distribution of equipment and the other for directing the proposed treatment.

All participants were instructed to wear appropriate clothes for aquatic practice; they were also oriented on how to behave in an aquatic environment.

Participants from the CG did not receive any physiotherapy in two months. Weekly phone calls were done in order to follow them up.

\section{Statistical analyses}

Data were analyzed using Statistical Package for Social Sciences Version 20 (SPSS v21.0). Descriptive statistics including means and standard deviations of baseline score and post-physiotherapy score for each measure were used to summarize the data. Comparison for potential confounders between the groups and in relation to evolution after the follow-up was done via the nonparametric chi-square test, Fisher's exact test and the Kruskal-Wallis test. Statistical significance was considered when $p<0.05$.

\section{Results}

In total, 29 elderly with knee OA participated of the study. The IG consisted of 15 women and 2 men, and CG was composed of 10 women and 2 men. There was a sample loss in the CG of four participants, three of them by dropping out and one by having performed an infiltration in the knee.

Comparisons among socio demographic variables showed no significant differences between IG and CG groups $(p<0.05)$ regarding potential confounders (Table 2). The same occurred with dependent variables (pain, stiffness and physical disability, related to physical and functional aspects, mobility and functional capacity), demonstrating a homogeneous distribution of the sample.

Comparing the variables after the intervention (pain, stiffness and physical disability, related to functional capacity aspects, and mobility), we observed that participants in the IG obtained statistically significant changes of all variables compared to the CG (Table 3).
Table 2 - Comparison between the intervention group (IG) and control group (CG) regarding potential confounders

\begin{tabular}{lccc}
\hline Variables & IG (n= 17) & CG (n= 12) & p-value \\
\hline Socio demographic & & & \\
Male & $2(12 \%)$ & $2(17 \%)$ & - \\
Women & $15(86 \%)$ & $10(83 \%)$ & - \\
Age (years) & 63 & 64 & - \\
Functional capacity & & & \\
Pain & 300 & 288 & $0.987(2)$ \\
Stiffness & 125 & 88 & $0.637(2)$ \\
Physical disability & 825 & 1000 & $0,816(2)$ \\
Traveled distance (m) & 351 & 333 & $0.941(2)$ \\
Mobility & & & \\
TUG time (s) & 13 & 14 & $0.905(2)$ \\
\hline
\end{tabular}

Note: $T U G=$ Timed Up and Go Test.

Table 3 - Comparison between intervention group (IG) and control group (CG) in relation to outcomes after intervention

\begin{tabular}{lccc}
\hline Variables & IG $(\mathbf{n}=\mathbf{1 7})$ & $\mathbf{C G}(\mathbf{n}=\mathbf{1 2})$ & p-value \\
\hline Functional capacity & & & \\
Pain & -125 & 25 & $<0.001$ \\
Stiffness & -25 & 13 & $<0.001$ \\
Physical disability & -275 & 113 & $<0.001$ \\
Travelled distance $(\mathrm{m})$ & 45 & -7.5 & 0.001 \\
Mobility & & & \\
TUGT time (s) & -2.3 & -0.73 & $<0.001$ \\
\hline
\end{tabular}

Note: TUG = Timed Up and Go Test

\section{Discussion}

The sample of this study was characterized by individuals with 60 years of age or older, predominantly female. Similarly, Nevitt and Felson ${ }^{15}$ found that women with body mass index between 30 and 35 and aged over 50 years were the stereotype group for greater predisposition to the development of knee OA.

The functionality is essential for the elderlies to carry out their daily life activities independently; therefore, FC conservation is one of the main guidelines of physiotherapy treatments. $^{8}$

Alves et al. ${ }^{19}$ suggest that chronic diseases have a strong influence on the elderly FC. Furthermore, the $\mathrm{FC}$ is one of the most important benefits promoted by therapeutic intervention in the elderly and is directly 
related to independence and may contribute directly to their quality of life. ${ }^{20}$

Caromano and Candeloro ${ }^{21}$ highlighted that AP is a feature that uses physical, physiological and kinesiological effects arising from body immersion of the body in heated pool as an auxiliary resource of rehabilitation or prevention of functional alterations.

The main benefits of AP for individuals in treatment of knee OA are: reducing pain; maintenance or increase in joint range of motion and muscle strength; improvements in functional gait ability; relaxation and relief of muscle spasm; reduction in joint overload, stiffness and swelling. ${ }^{9}$

For Carregaro and Toledo, ${ }^{22}$ AP provides a lower intra-articular pressure and decreases the impact forces on the joints. The decreased gravity action inside the water makes an ideal environment for rehabilitation of individuals who require low weight-bearing forces or have limitations on land-based physiotherapy.

In their study, Barduzzi et al. ${ }^{8}$ showed significantly satisfactory results of elderly with knee OA functional capacity who underwent $A P$, with regard to improvements in the time of usual and fast gait, as well as going up and down stairs.

Aquatic physiotherapy presents evolution in the mobility of patients with knee OA, as shown in the significant improvement assessed by the TUG. The movement of water generates comfort and decreases pain, consequently the elderly can better perform their functions, improving their functional mobility. Decrease in joint pain and improvement in the elderly's functional tasks ensue benefits in psychological factors, selfconfidence and well-being. ${ }^{23-25}$

In conclusion, several studies ${ }^{8,26-29}$ confirm that AP programs benefit individuals with $O A$, providing increase in muscle strength and aerobic capacity, pain reduction, improvement of functional capacity and consequently improvement of quality of life.

\section{Conclusion}

Significant improvements in pain, stiffness, functional capacity, gait time and mobility were seen in participants from the AP programme when compared to elderly with knee OA who did not receive any physiotherapy treatment.
The limitations of this study were the sample loss that occurred during its development. For future studies with this theme, we suggest expanding the sample to better represent this segment of the population.

\section{Authors' contributions}

PJFVB and FPG supervised the research. Design and data collection were conducted by FPG, NSP, GOB. Tabulation, analysis and statistical interpretation of data by FPG and PRRJ. FPG, AO and GOB were responsible for the writing of the manuscript and creation of tables and charts. NSP and AO, for the text preparation according to the journal's guidelines. PRRJ and PJFVB reviewed the manuscript, and all authors have approved the final version here published.

\section{References}

1. DIEESE. Quem são os idosos brasileiros. 2020 [cited 2021 Aug 10]. Available from: https://www.dieese.org.br/ boletimespecial/2020/boletimEspecial01.html

2. Sacitharan PK. Ageing and osteoarthritis. Subcell Biochem. 2019;91:123-59. DOI

3. Alexandre TS, Cordeiro RC, Ramos LR. Fatores associados à qualidade de vida em idosos com osteoartrite de joelho. Fisioter Pesqui. 2008;15(4):326-32. DOI

4. Ebell MH. Osteoarthritis: rapid evidence review. Am Fam Physician. 2018;97(8):523-6. Full text link

5. Hana S, Aicha BT, Selim D, Ines M, Rawdha T. Clinical and radiographic features of knee osteoarthritis of elderly patients. Curr Rheumatol Rev. 2018;14(2):181-7. DOI

6. Biasoli MC, Izola LNT. Aspectos gerais da reabilitação física em pacientes com osteoartrose. Rev Bras Med. 2003;60(3): 133-6. Full text link

7. Gonçalves A. Physiotherapy intervention in knee osteoarthritis - hydrotherapy and physical activity: A systematic review [dissertation] Porto: Universidade Fernando Pessoa; 2011. Full text link 
8. Barduzzi GO, Rocha Jr PR, Souza Neto JC, Aveiro MC. Functional capacity of elderly with osteoarthritis who undergone to aquatic and land physical therapy. Fisioter Mov. 2013;26(2): 349-60. DOI

9. Ishik CYW. Ishik CYW. Fisioterapia aquática em reumatologia. In: Sacchelli T, Accacio LMP, Radl ALM. Fisioterapia aquática. Barueri: Manole; 2007. p. 241-58.

10. Hochberg MC, Chang RW, Dwosh I, Lindsey S, Pincus T, Wolfe F. The American College of Rheumatology 1991 revised criteria for the classification of global functional status in rheumatoid arthritis. Arthritis Rheumatol. 1992;35(5):498-502. DOI

11. Foley A, Halbert J, Hewitt T, Crotty M. Does hydrotherapy improve strength and physical function in patients with osteoarthritis - a randomized controlled trial comparing a gym based and a hydrotherapy based strengthening programme. Ann Rheum Dis. 2003;62(12):1162-7. DO|

12. Instituto Brasileiro de Geografia e Estatística. Censo Demográfico. São Paulo: IBGE; 2010. Full text link

13. Fernandes MI. Tradução e validação do questionário de qualidade de vida específico para osteoartrose WOMAC (Western Ontario McMaster Universities) para a língua portuguesa [master's thesis]. São Paulo: Universidade Federal de São Paulo; 2003. Full text link

14. Bellamy N, Buchanan WW, Goldsmith CH, Campbell J, Stitt LW. Validation study of WOMAC: a health status instrument for measuring clinically important patient relevant outcomes to antirheumatic drug therapy in patients with osteoarthritis of the hip or knee. J Rheumatol. 1988;15:1833-40. PubMed

15. Nevitt MC, Felson DT. Sex hormones and the risk of osteoarthritis in women: epidemiological evidence. Ann Rheum Dis. 1996;55(9):673-6. DOI

16. ATS Committee on Proficiency Standards for Clinical Pulmonary Function Laboratories. ATS statement: Guidelines for the six-minute walk test. American journal of respiratory and critical care medicine. Am J Respir Crit Care Med. 2002;166(1):111-7. DOI

17. Podsiadlo D, Richardson S. The timed "Up \& Go": a test of basic functional mobility for frail elderly persons. J Am Geriatr Soc. 1991;39(2):142-8. DOI
18. Guimarães LHCT, Galdino DCA, Martins FLM, Vitorino DFM, Pereira KL, Carvalho EM. Comparação da propensão de quedas entre idosos que praticam atividade física e idosos sedentários. Rev Neurocienc. 2004;12(2):68-72. DOI

19. Alves LC, Leimann BCQ, Vasconcelos MEL, Carvalho MS, Vasconcelos AGG, Fonseca TCO, et al. A influência das doenças crônicas na capacidade funcional dos idosos do Município de São Paulo, Brasil. Cad Saude Publica. 2007;23(8):1924-30.DOI

20. Santos JPM, Andraus RAC, Pires-Oliveira DAA, Fernandes MTP, Frâncica MC, Poli-Frederico RC, et al. Análise da funcionalidade de idosos com osteoartrite. Fisioter Pesqui. 2015;22(2):161-8. DOI

21. Caromano FA, Candeloro JM. Fundamentos da hidroterapia para idosos. Arq Cienc Saude Unipar. 2001;5(2):187-95. Full text link

22. Carregaro RL, Toledo AM. Efeitos fisiológicos e evidências científicas da eficácia da fisioterapia aquática. Movimenta. 2008;1(1):23-7. Full text link

23. Khruakhorn S, Chiwarakranon S. Effects of hydrotherapy and land-based exercise on mobility and quality of life in patients with knee osteoarthritis: a randomized control trial. J Phys Ther Sci. 2021;33(4):375-83. DOI

24. Knoop J, Steultjens MPM, Roorda LD, Lems WF, van der Esch $\mathrm{M}$, Thorstensson CA, et al. Improvement in upper leg muscle strength underlies beneficial effects of exercise therapy in knee osteoarthritis: secondary analysis from a randomised controlled trial. Physiotherapy. 2015;101(2):171-7. DOI

25. McAlindon TE, Bannuru RR, Sullivan MC, Arden NK, Berenbaum F, Bierma-Zeinstra SM, et al. OARSI guidelines for the non-surgical management of knee osteoarthritis. Osteoarthritis Cartilage. 2014;22(3):363-88. DOI

26. Ottawa Panel. Ottawa Panel evidence-based clinical practice guidelines for therapeutic exercises in the management of rheumatoid arthritis in adults. Phys Ther. 2004;84(10):934-72. PubMed

27. Foley A, Halbert J, Hewitt T, Crotty M. Does hydrotherapy improve strength and physical function in patients with osteoarthritis - A randomized controlled trial comparing a gymbased and a hydrotherapy-based strengthening programme. Ann Rheum Dis. 2003; 62:1162-7. DOI 
28. Bartels EM, Juhl CB, Christensen R, Hagen KB, DanneskioldSamsoe B, Dagfinrud $H$, et al. Aquatic exercise for the treatment of knee and hip osteoarthritis. Cochrane Database Syst Rev. 2016;3:CD005523. DOI

29. Franco MR, Morelhão PK, Carvalho A, Pinto RZ. Aquatic exercise for the treatment of hip and knee osteoarthritis. Phys Ther. 2017;97(7):693-7. DOI 